\title{
Networks, Commuting and Spatial Structures: An Introduction
}

\author{
Guest Editorial
}

Aura Reggiani

University of Bologna ${ }^{\text {a }}$

\author{
Piet Rietveld \\ Free University of Amsterdam ${ }^{b}$
}

The interaction between home and workplace has been a central component of urban and regional economics theories (Clark et al. 2003). These authors also emphasize that it is the continuing separation of jobs and residences which produces much of the commuting, and these links are as relevant in the polycentric city as in the monocentric city. However, "[i]n practice, the dispersal of job opportunities has created a much more complicated behavioural response to the linkage between work and residence" (Clark et al. 2003, p.201). The relation between land use (residential and employment location) and commuting seems therefore rather complex and worth further exploration, despite the voluminous literature already existing ${ }^{1}$ on this issue.

Modelling this interaction was already a key issue of analysis in the 1950s and 1960s, starting with the seminal work by Wilson (1967) on spatial interaction/entropy models. Attention was then paid to the relevance of distance-decay functions (Taylor 1971), to the relationship between population growth and commuting time (Gordon et al. 1991), and to the empirical regularities concerning the size distribution of cities $\left(Z i p f\right.$ 's law $\left.{ }^{2}\right)$, where the average city's growth seems to be related to changes in employment and commuting costs (Rossi-Hansberg and Wright 2006). In particular, it has been recognized that "[a]gglomeration and residential mobility of the population between different geographic locations are tightly connected to economic activities" (Eeckhout 2004, p.1429). In this context, the relevance of the morphology of spatial structure came to the fore (Batty 2005).

More recently, a great deal of attention has been given to the network concept-the idea that many spatial economic phenomena can be described by a network of interactions among agents, where interconnectivity and interoperability between the different economic systems play significant roles (Reggiani and Schintler 2005). In this approach, connectivity structures based on network topology are regarded as a fundamental factor influencing the complex pattern of systems' interaction and social/economic behaviour (Albert and Barabási 1999; Burt 1992; Redondo 2007). Such network embedding seems crucial, for example, to understanding the vulnerability and resiliency of commuter networks, the evolution of commuting flows

\footnotetext{
aaura.reggiani@unibo.it

${ }^{b}$ prietveld@feweb.vu.nl

1 The contribution by Clark et al. (2003) provides a substantial review in this respect.

${ }^{2}$ For a discussion of the empirics of city size distribution and urban growth on the basis of Zipf's law (1949), see, among others, Duranton (2002).
} 
and employment patterns, and the the development of hierarchical land use patterns over time (Friesz 2007; Reggiani and Nijkamp 2009).

Reflections on the relationships between networks and commuting-and hence on the role of connectivity and spatial structures-certainly constitute a focal point of current research.

That is the conceptual background of this Special Issue. The six contributions in this issue have been selected with two ends in mind: first, to provide new analytical insights into the modelling and analysis of (complex) transportation networks, as well as into the behavioural preferences of users; and second, to constitute a methodological platform from which to identify novel research directions.

The idea of this Special Issue originates from a Euro-NECTAR ${ }^{3}$ (Network for European Communication and Transport Activities Research) Conference, organized in Porto, Portugal, in May 2007. Within this framework, the editors wish to thank Álvaro Costa (University of Porto) and his staff for their great scientific input and organizational support.

From the papers presented at that conference, we have extracted six particular contributions that aim to analyse and map out network and commuting models, as well as-where possible-the related relationships, in the light of the underlying spatial structures.

In this framework, we can link the six papers as illustrated in Figure 1.

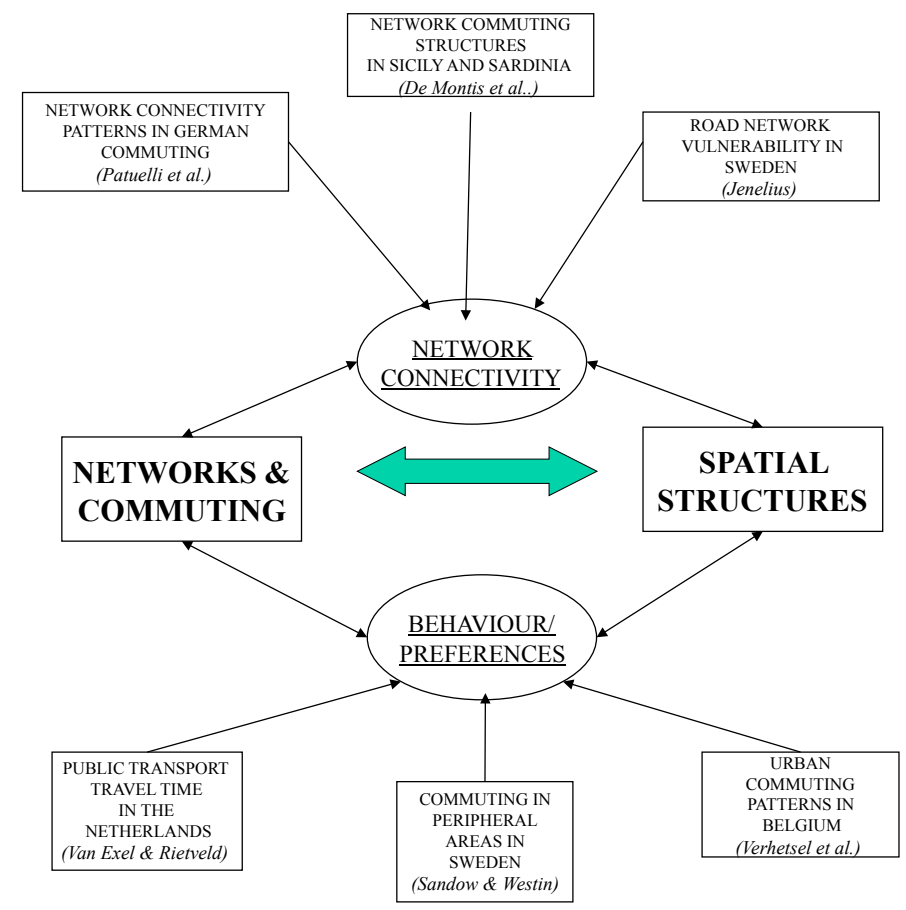

Figure 1: Structure of the methodological directions of, and linkages among, the papers in this Special Issue.

From Figure 1, it is clear that the research topics developed in the six papers can be grouped into two fundamental methodological perspectives:

\footnotetext{
${ }^{3}$ http://www.nectar-eu.org/
} 
1. The relevance of network connectivity and vulnerability in commuting/transportation patterns (Patuelli et al.; De Montis et al.; Jenelius).

2. The relevance of spatial structure in the behaviour and preferences of commuters (Van Exel and Rietveld; Sandow and Westin; Verhetsel et al.).

These two main issues are the focus of much current analytical and empirical research. Thus, we hope that this Special Issue can offer an overview of the recent methodological directions in commuting/transport networks, spatial choices, and their interactions with associated economic activities, in light of related policy implications.

Several research questions remain open, in particular, how the dynamics of network structures affect commuting and the interaction of these economic activities, and, hence, the relevance of 'dynamic' data provision and analysis, together with appropriate statistical tests for the verification of the underlying spatial economic processes.

The editors are grateful to all the authors and referees for their valuable and careful collaboration, and also for providing new insights and reflections on the issues mentioned above.

\section{References}

Albert, R. and L. Barabási. 1999. Emergence of scaling in random networks. Science, 286:509-512.

Batty, M. 2005. Cities and Complexity. Cambridge, MA: MIT Press.

Burt, R. 1992. The Structural Holes: The Social Structure of Competition. Harvard University Press.

Clark, W., Y. Huang, and S. Withers. 2003. Does commuting distance matter? commuting tolerance and residential change. Regional Science and Urban Economics, 33:199-221.

Duranton, G. 2002. City size distributions as a consequence of the growth process. CEPR Discussion Paper 3577, Centre for Economic Policy Research, London School of Economics and Political Science.

Eeckhout, J. 2004. Gibrat's law for (all) cities. The American Economic Review, 94(5):1429-1451.

Friesz, T., ed. 2007. Network Science, Nonlinear Science and Infrastructure Systems. International Series in Operations Research and Management Science. New York: Springer.

Gordon, P., H. Richardson, and M. Jun. 1991. The commuting paradox: Evidence from the top twenty. Journal of the American Planning Association, 57(4):416-420.

Redondo, F. V. 2007. Complex Social Networks. Cambridge, UK: Cambridge University Press.

Reggiani, A. and P. Nijkamp, eds. 2009. Complexity and Spatial Networks: In Search of Simplicity. Advances in Spatial Science. Berlin: Springer Verlag.

Reggiani, A. and L. Schintler, eds. 2005. Methods and Models in Transport and Telecommunications: Cross-Atlantic Perspectives. Advances in Spatial Science. Berlin: Springer Verlag.

Rossi-Hansberg, E. and M. Wright. 2006. Urban structure and growth. Research Dept. Staff Report 381, Federal Reserve Bank of Minneapolis.

Taylor, P. 1971. Distance transformation and distance decay functions. Geographical Analysis. Wilson, A. 1967. A statistical theory for spatial distribution models. Transportation Research, $1: 253-269$. 
Zipf, G. 1949. Human Behavior and the Principle of Least Effort. Cambridge, MA: AddisonWesley. 